ORIGINAL ARTICLE

\title{
Patterns and frequency of anxiety in women undergoing gynaecological surgery
}

\author{
Eloise Carr PhD, RGN, PGCEA, RNT \\ Senior Lecturer, Bournemouth University, Institute of Health and Community Studies, Bournemouth, Dorset, UK
}

Katrina Brockbank BSc, RGN, DPNS

Clinical Effectiveness Facilitator, Salisbury Healthcare NHS Trust, Salisbury, Wilts, UK

Sandra Allen BSc, MPH

188 Pine Road, Bournemouth, Dorset, UK

Paul Strike MPhil, C Stat, FSS

Medical Statistician, Salisbury Health Care NHS Trust, Salisbury, Wilts, UK

Submitted for publication: 13 May 2005

Accepted for publication: 17 May 2005

Correspondence:

Katrina Brockbank

Salisbury Road

Odstock Salisbury

SP2 8BJ

Telephone: 01722336262

E-mail: katrina.brockbank@salisbury.nhs.uk
CARR E, BROCKBANK K, ALLEN S \& STRIKE P (2005) Journal of Clinical Nursing 14, 1-12

Patterns and frequency of anxiety in women undergoing gynaecological surgery Aims. Within a gynaecological surgical setting to identify the patterns and frequency of anxiety pre- and postoperatively; to identify any correlation between raised anxiety levels and postoperative pain; to identify events, from the patients' perspective, that may increase or decrease anxiety in the pre- and postoperative periods. Background. It is well documented that surgery is associated with increased anxiety, which has an adverse impact on patient outcomes. Few studies have been conducted to obtain the patient's perspective on the experience of anxiety and the events and situations that aggravate and ameliorate it.

Method. The study used a mixed method approach. The sample consisted of women undergoing planned gynaecological surgery. Anxiety was assessed using the State Trait Anxiety Inventory. Trait anxiety was measured at the time of recruitment. State anxiety was then assessed at six time points during the pre- and postoperative periods. Postoperative pain was also measured using a $10 \mathrm{~cm}$ visual analogue scale. Taped semi-structured telephone interviews were conducted approximately a week after discharge.

Results. State anxiety rose steadily from the night before surgery to the point of leaving the ward to go to theatre. Anxiety then increased sharply prior to the anaesthetic decreasing sharply afterwards. Patients with higher levels of trait anxiety were more likely to experience higher levels of anxiety throughout their admission. Elevated levels of pre- and postoperative anxiety were associated with increased levels of postoperative pain. Telephone interviews revealed a range of events/situations that patients recalled distressing them and many were related to inadequate information.

Conclusion. This study found higher rates of anxiety than previously reported and anxiety levels appeared raised before admission to hospital. This has important clinical and research implications.

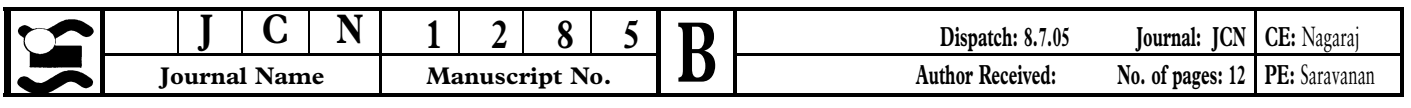


Relevance to clinical practice. Patients with high levels of anxiety may be identified preoperatively and interventions designed to reduce anxiety could be targeted to this vulnerable group. Patient experiences can inform the delivery of services to meet their health needs better.

Key words: anxiety, gynaecology, nursing, pain, STAI, surgery

\section{Introduction}

Anxiety, which is considered to be an emotional response to a perceived threat or danger (Spielberger \& Rickman 1990), is present in most surgical patients to a certain degree (Norris \& Baird 1967, Ramsey 1972, Johnston 1980, WilsonBarnett 1981, Welsh 2000). For women undergoing gynaecological surgery, anxiety is recognized as an important factor because of the sensitive and emotive nature of their treatment (Walsgrove 1999). Research has shown that women with gynaecological disorders undergoing invasive radiological procedures experience higher levels of state anxiety than other invasive radiological procedures (Aksoy et al. 2000). It has also been demonstrated that women undergoing gynaecological surgery, who expressed more worry before their surgery, displayed greater heart rate and blood pressure changes before and during surgery, and were more difficult to anaesthetize, and were more likely to experience headache, vomiting and pain afterwards (Abbott \& Abbott 1995). Preoperatively, anxiety may be due to threats to the patient's self-concept, role functioning, fear of alteration in body image, having an anaesthetic, pain, discomfort and dependence (Wilson-Barnett 1981, Dodds 1993, Salmon 1993, Welsh 2000, Cheung et al. 2003). Postoperatively, the patient's need to ambulate and attend their own hygiene needs have been identified as important, and the need for effective communication between all members of the health care team (Manias 2003, Nijkamp

1 et al. 2005). Raised anxiety has important clinical implications as it has been demonstrated to have an adverse impact

2 upon anaesthetic requirements (Osborn \& Sandler 2004),

3 postoperative recovery (Kiecolt-Glaser et al. 1998), as well as increasing the likelihood of postoperative nausea and vom-

4 iting (Van den Bosch 2005). Numerous studies have demonstrated a positive correlation between anxiety and pain with less anxious patients experiencing less pain 5(Thomas et al. 1995, De Groot et al. 1997, Kain et al. 2000, Kalkman et al. 2003). It has also been shown that the anxious patient tends to require a longer postoperative hospital stay (Boeke et al. 1991) and can result in behavioural and cognitive sequelae that can also have far- reaching effects on recovery (Wilson-Barnett \& Batehup 1988, Kiecolt-Glaser et al. 1998).

The majority of studies, concerned with anxiety prior to surgery, measure the variable at only one time point preoperatively (Salmon et al. 1986, Tatrow et al. 2004, Ukpong \& Adesunkanmi 2004). The identification and understanding of anxiety as experienced by surgical patients are vital given that assisting patients in coping with anxiety are recognized as one of the nurse's most important responsibilities (Swindale 1989, Teasdale 1995, Cunado Barrio et al. 1999, Mitchell 2000, Manias 2003, Moser et al. 2003). Previous research has suggested that nurses do not accurately perceive anxiety and stress in surgical patients (Biley 1989, Teasdale et al. 2000). Whilst there has been a wealth of research conducted on anxiety in surgical patients, surprisingly little research has been conducted on the natural course of such anxiety. This may be seen as important not only to enhance the understanding of the patient experience, but also for the successful implementation of anxiety management interventions. There have been few studies that have considered the experience of anxiety from the patient's perspective. Grieve (2002) asked 150-day surgery patients to describe how they felt about their impending surgery. Whilst this provided valuable insight into the patient's experience, again the focus was on the immediate preoperative period only. It would appear that there is a paucity of knowledge regarding this experience of anxiety over time and the factors that might influence this in the clinical setting.

\section{Aims}

The aims of this study were to:

- To identify the frequency and pattern of anxiety in the immediate pre- and postoperative periods;

- To identify any correlation between raised anxiety levels and postoperative pain;

- To identify what events/situations, from the patients' perspective, may contribute to an elevation or decrease in anxiety levels in the immediate pre- and postoperative periods. 


\section{Design}

The study used a mixed-method design. The mixing of quantitative and qualitative methods for evaluative purposes has been referred to as 'mixed-methods' and is most frequently used for the purpose of method triangulation 6,7(Green \& McClintock 1985, Paraho 1997, Shih 1998, Barbour 1999). Triangulation has been defined as the combination of two or more theories, data sources, methods, or investigators in one study of a single phenomenon' (Shih 1998, p. 632). This mixed methods framework was deemed essential as the study had a dual purpose; to investigate the frequency of anxiety as well as gain an insight into the patients' anxiety experience. The aim of this triangulation was to obtain a more complete and holistic understanding of anxiety as experienced by

8surgical patients (Jick 1979, Coyle \& Williams 2000).

\section{Sample}

A convenience sample of 80 women undergoing planned gynaecological surgery was used. The inclusion criteria were that all women were aged over 18 years, and were having planned gynaecological surgery. Women were excluded from the study if they suffered cognitive dementia or confusion. A sample size of 80 is consistent with the 'rule of thumb' minimum for regression studies: at least 10 subjects per variable entered into the regression model (Norman \& Streiner 2000). We have eight candidate risk factors.

\section{Data collection}

Women attending the preadmission clinics, approximately one week prior to surgery, were invited to participate in the study. Following consent, a baseline measure of trait anxiety and demographic variables were obtained. The latter comprised age, marital status, nature of operation, and historical data including previous surgery and previous pain. State anxiety was subsequently measured at six time points; $6 \mathrm{PM}$ the night before surgery, $8 \mathrm{Am}$ or on waking the morning of surgery, before leaving the ward to go to theatre, in the anaesthetic room, $8 \mathrm{Am}$ one day postoperatively and 8 AM day two postoperatively. The preoperative questionnaires were given to the patients to administer themselves. On postoperative days one and two, after completing the STAI, pain was also measured using a visual analogue scale (VAS). Taped semi-structured telephone interviews were conducted with the patients approximately one week after discharge from hospital. Invitation to participate in the study and data collection was undertaken by SA and KB.

\section{Research instruments}

\section{State-trait anxiety inventory}

Anxiety was assessed using the State Trait Anxiety Inventory (STAI), which was designed by Spielberger et al. (1970). The STAI is a widely used self-report anxiety measurement tool, which consists of two 20-item scales, which enquire about feelings. The STAI Form X-1 is designed to measure the transitory or situational emotional states (state anxiety) and inquires about feelings on a four-point Likert scale, with responses ranging from 1 (not at all) to 4 (very much). The STAI Form X-2 is designed to inquire about how the person feels in general (trait anxiety), which is the relatively stable individual differences in anxiety proneness. The 20-item scales explore how the person feels and the four-point Likert scale ranges from 1 (almost never) to 4 (almost always). The possible scores for each form range from 20 to 80, a higher score indicating a greater level of anxiety. Reliability and validity of the STAI are well reported (Spielberger et al. 1970, 9Spielberger et al. 1983, Munafo \& Stevenson 2001).

\section{Visual analogue scale}

The VAS consisted of a $10-\mathrm{cm}$ horizontal line with verbal anchors at either end (no pain and worst pain imaginable) and is one of the most widely used assessment tools in the measurement of pain (Gudex et al. 1996, Briggs \& Dean 1998). Patients were asked to indicate their current pain on movement by placing a mark on the horizontal line. Whilst there have been criticisms concerning the users ability to understand the instrument (Chapman et al. 1985, McDowell

$10 \&$ Newell 1987) with clear instructions, the simplicity appears to outweigh the limitations (Coll et al. 2004).

\section{Additional patient data}

Information in addition to basic demographics was also collected: type of surgery, history of previous surgery, if the surgery was related to a possible malignancy, whether the patient had received night sedation the night before the surgery, whether the patient had received premedication, and if the patient suffered from pain prior to admission. Information was obtained either from the patients directly or their medical records.

\section{Semi-structured telephone interviews}

To identify events or situations, from the patients' perspective, that may have contributed to an elevation or decrease in anxiety levels, a semi-structured taped telephone interview was conducted a week after discharge from hospital. This method of data collection was chosen as its format provides a structure and focus to the interview, whilst also containing a 
flexibility which allows for probing of more complex and sensitive issues (Barriball \& While 1994, Waterman et al. 1999, Carr \& Worth 2001). These interviews were taped as this permitted an identical replication of the interview, which facilitated analysis as well as reduced the possibility of error (Barriball \& While 1994). Given the large volume of potential data, it was planned that interviews would stop when no new data emerged.

The importance of authenticity in qualitative research demands that terms such as transferability, dependability, confirmability and credibility are explored (Holloway \& Wheeler 1996). A co-researcher, who was familiar with the surgical experience but not the study, coded every seventh transcript, interpreting the data to confirm the meanings. These were shared with SA and mutually agreed themes and sub-themes were confirmed.

\section{Ethical considerations}

Ethical approval for the study was obtained from the Research and Ethics Committee (REC). Patients were approached in the preadmission assessment clinic, where they were given information about the study. Due to time constraints, informed consent to participate was obtained at this point. Later in the study, verbal consent was gained to proceed with the telephone interview as it is important to recognize that, during the time between written consent and the interview, the patients' views may change (Carr \& Worth 2001).

\section{Data analysis}

The quantitative data were managed in a database constructed in Microsoft Access. The data were analysed using a combination of the Statistical Package for the Social Sciences (SPSS) version 10, Minitab version 14 and the logistic regression and modelling package EGRET. v.2. In response to the non-normal distribution of the state anxiety (Anderson-Darling Normality test: $P<0.05$ ), nonparametric statistical methods (Wilcoxon paired-sample test and Friedman repeat measures analysis of variance) were used in the assessment of observed changes in anxiety across key time points. The Mann-Whitney test (independent sample comparisons), Spearman rank correlation (bivariate associations) and logistic regression modelling were used to assess interelationships between anxiety and pain scores, and to evaluate candidate predictors of high anxiety, respectively.

Patients classified as a 'high' anxiety patient if scored $\geq 45$ on the STAI which follows that adopted by other studies
11(Spielberger et al. 1973, Nelson et al. 1998, Kindler et al. 2000, Teasdale et al. 2000).

A pragmatic thematic analysis of the semi-structured interviews was undertaken (Aronson 1994). Interviews were transcribed and coded to reduce the data (Miles \& Huberman 1994). Codes were grouped together into a smaller number of constructs if they were found to pertain to the same aspect of the phenomena, which formed themes and sub-themes.

\section{Results}

One hundred and twelve patients were asked to participate in the study; 94 patients (83.9\%) consented, 11 (9.8\%) declined and seven $(6.3 \%)$ were not included because they either did not understand the questionnaires or were having day case surgery. Fourteen patients were withdrawn from the study due to: surgery postponed or cancelled, incomplete data, or transferred to general surgeons. Forty-four women participated in semi-structured interviews. Initially, it was hoped to interview each women, however, due to time constraints and also a lack of new emerging data, interview data collection ceased at this point. Data were collected between October 2001 and May 2002.

The mean age was 52.1 years (SD 13.96) and range 1882 years. Patients were categorized as having major surgery (abdominal incision, $n=40)$ or minor surgery $(n=40)$ with the most common major surgical procedure being total abdominal hysterectomy $(n=28,35 \%)$ and the most common minor procedure being vaginal hysterectomy $(n=15$, $18 \cdot 7 \%)$. A total $86 \cdot 3 \%(n=69)$ of the women had previously surgery and $22(27 \cdot 5 \%)$ reported preadmission pain. The mean postoperative length of stay was 3.8 days (SD $2 \cdot 13)$. The median trait anxiety was 40.5 with an interquartile range of $32-48 \cdot 75$. Table 1 summarizes the frequency of anxiety in the sample using the external reference value of STAI $\geq 45$. At the preadmission clinic, nearly half of the patients $(41 \cdot 3 \%)$ experienced 'high' anxiety. Preoperatively, the greatest frequency of 'high' anxiety was seen at the preanaesthetic time point, where $67 \%$ of the sample were 'high' anxiety cases. Postoperatively, the of 'high' anxiety decreased considerably to $20 \%$ on day one and $19 \%$ on day two.

12 The variation between patients in anxiety levels over the study period was extensive but a statistically significant pattern of change (Friedman $P<0.0001$ ) is evidenced in the summary anxiety profile (Fig. 1). Subsequent pairwise contrasts between median trait anxiety scores at selected time points were evaluated using the Wilcoxon signed-ranks test. Preoperatively, there was little observed difference between 
Table 1 Frequency of anxiety in the sample using an external reference value (STAI score $\geq 45$ )

\begin{tabular}{llll}
\hline Time point & $n$ (valid) & Frequency $\geq 45$ & $\%$ \\
\hline TS & 80 & 33 & $41 \cdot 3$ \\
S1 & 78 & 39 & $44 \cdot 9$ \\
S2 & 78 & 35 & $52 \cdot 7$ \\
S3 & 56 & 29 & $51 \cdot 8$ \\
S4 & 21 & 14 & $66 \cdot 7$ \\
S5 & 75 & 15 & 20 \\
S6 & 74 & 14 & $18 \cdot 9$ \\
\hline
\end{tabular}

Keys - S1, state anxiety 6 PM night before surgery; S2, state anxiety 8 AM morning of surgery; S3, state anxiety before leaving ward for surgery; S4, state anxiety prior to anaesthetic; S5, state anxiety day one postoperatively; S6, state anxiety day two postoperatively.

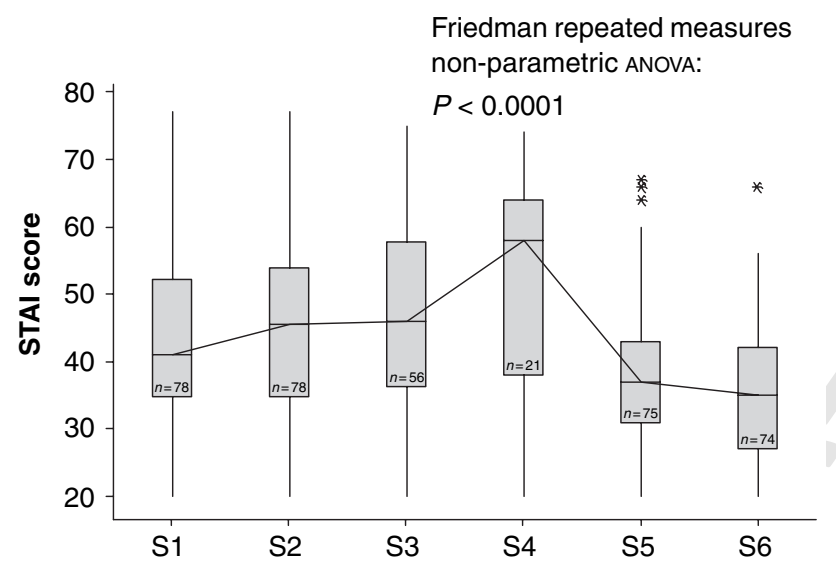

Figure 1 Summary anxiety profile using boxplots of STAI scores over study period. Keys - see Table 1.

the median preadmission clinical trait anxiety score (40.5) and the median state anxiety score the night before surgery (41). Anxiety levels peaked at the preanaesthetic time point (median $=58)$. The median anxiety prior to the anaesthetic was significantly higher than the median anxiety the evening before surgery $(P=0 \cdot 0001)$, which is not unexpected due to the proximity to surgery. There was a sharp decline in median state anxiety from the preanaesthetic time point (58) to day one postoperatively (37) $(P=0.03)$.

The median pain score on day one postoperatively was $3 \cdot 4$ declining on day two to $2 \cdot 1$ (Wilcoxon $P=0 \cdot 02$ ). Elevated levels of preoperative state anxiety on the night before surgery were weakly associated with increased levels of postoperative pain on day one $\left(r_{\mathrm{s}}=0.254, P=0.031\right)$ and day two $\left(r_{\mathrm{s}}=0.295, P=0.011\right)$. A positive correlation was also observed between postoperative state anxiety and postoperative pain on day one $\left(r_{\mathrm{s}}=0.382, P=0.001\right)$ and day two $\left(r_{\mathrm{s}}=0.515, P<0.0001\right)$. No significant associations were identified between trait anxiety and postoperative pain.

\section{Predictors of anxiety}

To facilitate the search for possible predictors of a propensity to 'high' anxiety, we used a summary measures approach to repeated measures analysis (see Senn et al. 2000) to capture each patient's profile of trait anxiety scores. The summary measures approach to the analysis of serial measurements is a simple and effective alternative to techniques such as repeated measures analysis of variance (rm-ANOvA), when confronted by missing values, variable timings, outliers and non-normal distribution. The methodology is described in practical detail by Altman (1991). The summary measure used was the area under the patient's anxiety response profile (Area Under Curve or AUC). Eight variables relating to the study subjects (see Table 2) were examined, individually (univariate analysis) and collectively (multivariate analysis) to assess possible associations with our composite anxiety measure (AUC). Univariate analysis, using the Mann-Whitney test or the Spearman correlation as appropriate, revealed three significant variables, major or minor surgery $(P=0.002)$, previous pain $(P=0.007)$ and trait anxiety $(P<0.0001)$. All eight variables were then entered into a logistic regression, using AUC as the outcome variable, this being dichotomized at the 50 th centile i.e. 'low' anxiety (AUC $<50$ th centile) and 'high' anxiety (AUC > 50th centile). The results reveal two significant predictors, major or minor surgery and trait anxiety (Table 2). Both forward and backward stepwise variable selection delivered a reduced model comprising only these two variables (Table 3 ). A repetition of the analysis using the 75 th centile as a 'high' anxiety threshold delivered a reduced equation comprising state anxiety and history of previous pain as significant predictors (Table 4). No significant interactions between variables were detected. No model fit pathologies were detected, using the suite of diagnostics resident in EGRET. The reduced model equations classified 84 and $87 \%$ of the study subjects correctly in terms of their anxiety status using the 50th and the 75th centile 'high' anxiety cut-offs, respectively. We conclude that trait anxiety, type of surgery (major or minor) and previous pain are key players in the identification of propensity to high anxiety.

There was a clear correlation between the patients' preadmission trait anxiety score and the overall anxiety profile (AUC 50) over time $\left(r_{\mathrm{s}}=0.587, P<0.001\right)$. This indicates that those patients with higher levels of anxiety proneness are more likely to experience higher levels of anxiety throughout the admission period. Women who were admitted for major surgery $(n=40)$ were significantly more anxious than those women who were admitted for minor surgery $(n=40)$ (Mann-Whitney $P=0 \cdot 002)$. Women who reported pain prior to hospital admission (demographic data) 


\begin{tabular}{|c|c|c|c|c|c|c|c|}
\hline \multirow[b]{2}{*}{ Predictor } & \multirow[b]{2}{*}{ Coeff. (beta) } & \multirow[b]{2}{*}{ SE } & \multirow[b]{2}{*}{$Z$} & \multirow[b]{2}{*}{$P$-value } & \multirow[b]{2}{*}{ Odds ratio } & \multicolumn{2}{|c|}{$95 \% \mathrm{CI}$} \\
\hline & & & & & & Lower & Upper \\
\hline Constant & $-5 \cdot 90$ & $2 \cdot 51$ & $-2 \cdot 35$ & $0 \cdot 02$ & & & \\
\hline Age & $0 \cdot 001$ & $0 \cdot 03$ & $0 \cdot 02$ & 0.99 & $1 \cdot 00$ & $0 \cdot 94$ & $1 \cdot 06$ \\
\hline Major/minor & $2 \cdot 21$ & 0.92 & $2 \cdot 40$ & $0 \cdot 02$ & $9 \cdot 14$ & $1 \cdot 50$ & $55 \cdot 82$ \\
\hline Previous surgery & $0 \cdot 43$ & $0 \cdot 91$ & $0 \cdot 47$ & $0 \cdot 64$ & $1 \cdot 54$ & $0 \cdot 26$ & $9 \cdot 08$ \\
\hline Premedication & $1 \cdot 87$ & $1 \cdot 35$ & $1 \cdot 39$ & $0 \cdot 17$ & $6 \cdot 52$ & $0 \cdot 46$ & $92 \cdot 20$ \\
\hline Night sedation & $-0 \cdot 04$ & $1 \cdot 11$ & $-0 \cdot 04$ & 0.97 & $0 \cdot 96$ & $0 \cdot 11$ & $8 \cdot 53$ \\
\hline Surgical cancer & $-1 \cdot 68$ & $1 \cdot 09$ & $-1 \cdot 55$ & $0 \cdot 12$ & $0 \cdot 19$ & $0 \cdot 02$ & $1 \cdot 57$ \\
\hline Previous pain & $1 \cdot 08$ & $0 \cdot 80$ & $1 \cdot 34$ & $0 \cdot 18$ & $2 \cdot 94$ & $0 \cdot 61$ & $14 \cdot 21$ \\
\hline Trait & $0 \cdot 10$ & $0 \cdot 04$ & $2 \cdot 87$ & $0 \cdot 004$ & $1 \cdot 11$ & $1 \cdot 03$ & $1 \cdot 19$ \\
\hline
\end{tabular}

\begin{tabular}{|c|c|c|c|c|c|c|c|}
\hline \multirow[b]{2}{*}{ Predictor } & \multirow[b]{2}{*}{ Coeff. (beta) } & \multirow[b]{2}{*}{ SD } & \multirow[b]{2}{*}{$Z$} & \multirow[b]{2}{*}{$P$-value } & \multirow[b]{2}{*}{ Odds ratio } & \multicolumn{2}{|c|}{$95 \% \mathrm{CI}$} \\
\hline & & & & & & Lower & Upper \\
\hline Constant & $-5 \cdot 910$ & $1 \cdot 481$ & -3.99 & $<0.001$ & & & \\
\hline Trait & $0 \cdot 124$ & 0.033 & $3 \cdot 72$ & $<0.001$ & $1 \cdot 13$ & $1 \cdot 06$ & $1 \cdot 21$ \\
\hline Major/minor & $1 \cdot 884$ & 0.596 & $3 \cdot 16$ & 0.002 & $6 \cdot 58$ & $2 \cdot 04$ & $21 \cdot 17$ \\
\hline
\end{tabular}

\begin{tabular}{|c|c|c|c|c|c|c|c|}
\hline \multirow[b]{2}{*}{ Predictor } & \multirow[b]{2}{*}{ Coeff. (beta) } & \multirow[b]{2}{*}{ SD } & \multirow[b]{2}{*}{$Z$} & \multirow[b]{2}{*}{$P$-value } & \multirow{2}{*}{$\begin{array}{l}\text { Odds } \\
\text { ratio }\end{array}$} & \multicolumn{2}{|c|}{$95 \% \mathrm{CI}$} \\
\hline & & & & & & Lower & Upper \\
\hline Constant & $-8 \cdot 566$ & $2 \cdot 179$ & -3.93 & $<0.001$ & 7 & V & \\
\hline Trait & $0 \cdot 154$ & $0 \cdot 044$ & $3 \cdot 51$ & $<0 \cdot 001$ & $1 \cdot 17$ & $1 \cdot 07$ & $1 \cdot 27$ \\
\hline Previous pain & $1 \cdot 582$ & $0 \cdot 762$ & $2 \cdot 08$ & 0.038 & $4 \cdot 86$ & $1 \cdot 09$ & $21 \cdot 63$ \\
\hline
\end{tabular}

Table 2 Logistic regression: dichotomizing the AUC variable on the 50th percentile: $(\geq 50$ th percentile $=$ 'high' anxiety, $n=77$ )

Table 3 Reduced model for logistic regression: dichotomizing the AUC variable on the 50th percentile: $(\geq 50$ th percentile $=$ 'high' anxiety, $n=77$ )

Table 4 Reduced model for logistic regression: dichotomizing the AUC variable on the 75 th percentile: $(\geq 75$ th percentile $=$ 'high' anxiety, $n=77$ ) were also significantly more anxious during the study period than those who did not (Mann-Whitney $P=0.006$ ).

\section{Qualitative analysis}

Forty-four $(55 \%)$ women were interviewed by telephone. When it became apparent that no new data were being obtained from the interviews, they were stopped. Thematic analysis revealed the two key themes 'causes of anxiety' and 'alleviation of anxiety' (Tables 5 and 6).

It was evident from the questionnaire data that the preoperative period was an anxious time. The organization and delivery of care could increase anxiety through cancellation of surgery, excessive waiting times and staff attitudes:

I was feeling very worried, and I wasn't feeling well at all that day, and to be told that day that I wasn't going in. I didn't know if I was going to be able to cope with the rest of that day. (p. 2)

I had to be in for 1.30 and absolutely nothing at all was checked or done with me on that day at all. So I went in from 1.30 and stayed there all afternoon for absolutely no good reason at all. (p. 40)
I could overhear the nurse and the patient, she wanted a commode and it was used and I don't think she was able to wipe her own bottom and the nurse refused to do it for her...the woman ended up in tears...that did bother me and I still think about it now. (p. 68)

Whilst being admitted to hospital and becoming a patient is acknowledged as stressful the loss of independence together

Table 5 Sub-themes and codes for the key theme: 'causes of anxiety'

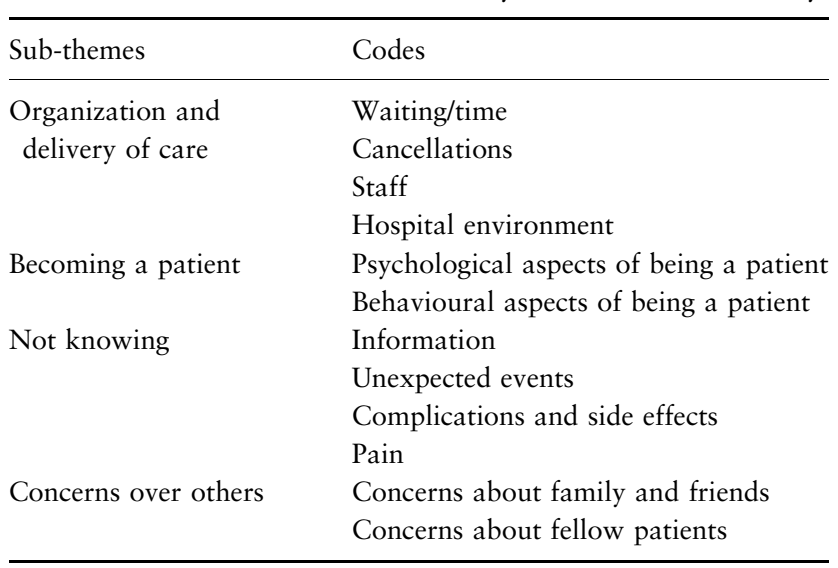


Table 6 Sub-themes and codes for the key theme: 'alleviating anxiety'

\begin{tabular}{ll}
\hline Sub-theme & Codes \\
\hline People & Hospital staff \\
& Other patients \\
& Family and friends \\
& Returning to self \\
Being prepared & Previous experiences \\
& Accurate information \\
Pain & Good pain management \\
\hline
\end{tabular}

with unexpected feelings of helplessness and vulnerability contributed to this.

It was awful, the clinic was full of screaming kids and I was in my nightie and slippers everyone else was in their outdoor clothes. It had been raining and they were all in coats and I was in my nightie. I was pushed to one side of the room and I just sat there and felt very nervous and really very vulnerable. (p. 21)

I just found the whole experience very strange, you know, I lead an extremely busy life normally and look after myself, and when you are stuck in bed in a nightie you begin to feel very odd, as if you are totally not yourself and out of control. (p. 16)

The further sub-theme to emerge was 'not knowing' and several examples of lack of information or being given conflicting advice contributed to feeling anxious:

Most people do have this loss after they have this type of operation and at no point was I told how long this was likely to go on. (p. 37)

...my consultations were, one of them was inaccurate, the consultant had to write to me afterwards to correct what the doctor had told me at the consultation. (p. 10)

...pain, that was what I was more concerned about...pain really. (p. 48)

Whilst fellow patients could elicit feelings of anxiety, patients also tried to reduce their distress:

Well when you are in a ward like that you hear other people being ill. Yes, I worry about the other people who are obviously in distress. (p. 68)

I spoke to two or three patients while I was on the ward because they looked very anxious and worried and a bit alone. (p. 51)

Patients also identified situations where their anxiety was alleviated, in particular fellow patients and healthcare workers:

One thing that really, really helped, there was another lady on the ward... and we got on like a house on fire. I was talking to her the evening before the operation, all the same sort of anxieties...everything that I'd worried about she'd got exactly the same...and that really helped. In fact she was one of the best things about the whole thing, I can honestly say. (p. 34)

You weren't just a number you know, we've done number four and now its number six. You actually felt you were a real person and they all knew who you were. (p. 56)

Being prepared and knowing what to expect also contributed to the alleviation of anxiety:

All my meetings with all the doctors, all my appointments...were very informative. Not at one time did they ever put me at the stage where I got frightened of what might happen. (p. 15)

Good pain management was viewed as an important component of care that reduced anxiety:

I came to and they said 'any pain, any pain' and I kept saying 'no, no, no', and I thought I must be out of the ordinary because I didn't have any pain. (p. 8)

I was given all the pain relief I needed when I wanted it. (p. 48)

The interviews gave a rich insight into the subjective experience of anxiety, and in particular, to further understand the events and situations that caused a rise or fall in anxiety levels associated with hospitalization for surgery.

\section{Discussion}

The primary aims of this study were to identify the frequency and patterns of anxiety before and after surgery, identify any correlation between pain and anxiety, and gain an understanding of the events that heighten or lessen anxiety at this time. Implications for the delivery of care and suggestions are made for where improvements might ameliorate anxiety for the surgical patient.

\section{Frequency and patterns of anxiety}

The frequency of high levels of trait anxiety within the sample was greater than expected, with almost half of the sample scoring $\geq 45$ on the STAI. Mean trait anxiety for female general population has been reported as 36.85 (Knight et al. 1983). Despite apparently high levels of preoperative state anxiety within the study population, these levels may be considered lower than perhaps would be expected, bearing in mind the nature of the sample. Patients in the study were undergoing gynaecological surgery, which is associated with high rates of psychological morbidity (Lalinec \& Engelsmann 131985, Salter 1985, Ryan et al. 1989, Abbott \& Abbott 1995). 
Therefore, this group of patients is vulnerable and may have additional psychological needs.

The absence of any noteworthy difference between median preadmission clinic trait anxiety score (40.5) and median state anxiety score the evening before surgery (41) was surprising, and raises questions regarding the time point at which the impending surgery impacts upon anxiety levels. The findings from the qualitative analysis suggested that anxiety levels were raised in advance of admission. For example, the prospect of surgical cancellation had resulted in increased anxiety before admission.

In the current study, the individual differences in the anxiety profiles were highly variable between women. It is acknowledged that patients do differ in their psychological response to hospitalization, and in particular to surgery (Kincey 1995). These findings emphasize the importance of individualized care and the recognition of individual variance and subsequent interventions to reduce anxiety.

A general pattern of anxiety over the study period was seen to emerge, where anxiety rose during the preoperative period to a peak prior to the anaesthetic, and then declined sharply on day one postoperatively, with little observed change on day two. This pattern is generally supported within the literature in spite of variations in study design (De Groot et al. 1997, McCrone et al. 2001).

\section{Pain and anxiety}

This study revealed that women with elevated levels of preoperative anxiety were more likely to experience a higher level of pain postoperatively (Perry et al. 1994, Kain et al. 2000). Uncertainty is evident in the literature regarding the role of preoperative anxiety on postoperative pain as some studies have reported that it is trait and not state anxiety that is the important predictor variable for postoperative pain (Munafo \& Stevenson 2001). Kain et al. (2000) provide evidence that the trait anxiety in itself does not have any direct effect on postoperative pain, but that the effects of trait anxiety were mediated through the effects of anxiety on preoperative state anxiety (Kain et al. 2000). It would appear that the majority of studies supports the relationship between anxiety and pain but methodological weaknesses and confounding variables (different patient groups) may be responsible for the reported inconsistencies.

Early identification of patients with 'high anxiety' would enable interventions to be targeted to this group. Even though the educational and managerial implications associated with such interventions are acknowledged (Wilson-Barnett 1994), targeting a 'high risk' group as opposed to the whole patient population may be seen as a better use of scarce resources.
Similarly, in the postoperative period, the current study also found that postoperative anxiety was positively correlated with postoperative pain. Good pain management was identified by the women as a significant contributor to the alleviation of anxiety and conversely, pain itself could elicit anxiety. It is important to emphasize that such findings do not explain the direction of the relationship between postoperative anxiety and pain, whether anxiety makes the experience of pain worse or whether pain leads to increased anxiety (Carr 2000). These associations between anxiety and pain not only reinforce the clinical importance of anxiety but also suggest avenues through which pain management strategies can be developed.

\section{Events and situations increasing or decreasing anxiety}

From the interviews, a range of events/situations that influenced anxiety were identified. Not knowing whether a hospital bed was available until the day of admission and being admitted the night before surgery, there were events, for some patients, that contributed to their anxiety (Koivula et al. 2002, Ivarsson et al. 2004). Such findings suggest instances where the organization and delivery of care are not grounded in the patients' viewpoint. Tasa et al. (1996) state that the creation and change in policies and service delivery are often based on criteria that are deemed of importance to the organization rather than the patient. Improvements in the health care organization including better information and support and a change of waiting lists systems were recommended. It is clear that interventions designed to reduce anxiety may need to be instigated prior to hospital admission if they are to impact on the sustained levels of anxiety during the admission period. With the decline in the use of preoperative anxiolytic drugs, it is unlikely that these would be prescribed to address the distress experienced prior to hospitalization. However, other interventions such as relaxation therapy and cognitive behavioural therapy may be of benefit. Further research is needed in this area.

There were many reported events that patients recalled distressing them and many were related to inadequate information. The importance of providing preoperative information to help patients reduce their anxiety is well reported (Devine 1992, Johnston \& Vogele 1993, Gammon \& Mulholland 1996, Sjoling et al. 2003). The increasingly shorter hospital stay challenges health care professionals to provide information that prepares patients adequately for surgery.

Grieve (2002) conducted a qualitative study in a day surgery unit where patients were asked via open questioning to describe how they felt about their impending surgery. A central feature reported by the patients, which compounded their anxiety, was 
the loss of personal identity and control, leading to a sense of disempowerment. Webb (1986) wrote of her experiences of becoming a gynaecology patient and used this experience to further inform the study she undertook. Her words are mirrored nearly 20 years later by a patient in this study:

Despite being an experienced nurse and a fairly confident woman in other realms of my life, I was reduced to feeling inadequate, a person who could not be talked to on an equal basis by doctors, and someone whose worries and distress were of no importance. (Webb 1986, p. 105)

Fellow patients were used as a source of information, as a distraction from current worries, and most importantly, as a forum for discussion and validation of emotions and physical symptoms. Kulik et al. (1996) found that patients engaged in more cognitive clarity and emotional self-evaluation affiliations with a roommate who had a similar rather than dissimilar surgical problem. Parent and Fortin (2000) found that patients who received support from former patients were less anxious before surgery, reported greater self-efficacy and increased physical activity postsurgery. This might be a helpful strategy for patients who are particularly anxious.

From the qualitative analysis, one of the strongest themes to emerge was the importance of the nurse-patient relationship for the alleviation and management of anxiety, the sense of being cared for as an individual rather than as an object of care. Support for these findings is provided by other published research into the patients' experience of nursing (Appleton 1993, Koch et al. 1995, Ersser 1998, Bouthillette

142001). In a study conducted by Astedt-Kurki and HaggmanLaitila (1992), patients, in describing their care, emphasized the importance of the interaction between patient and nurse. In particular, kindness, friendliness, sense of humour, as well as how well the nurse secured the intimacy and safety of the patient, were described as important components of nursing care. Whilst strategies to reduce anxiety might be thought of as 'relaxation' or 'information', it is also important to emphasize the therapeutic nature of individualized patient care.

\section{Limitations to the study}

There are several issues related to the methodological design of this study which need to be discussed. The decision to have a convenience sample, which included a broad sample of patients of different ages with different operations, was balanced against the need to capture a wide patient perspective, but obviously reducing the generalizability of these findings to other settings. The preoperative questionnaires were given to the patients to administer themselves due to practical and time constraints, which introduced the possibility of patients failing to complete the questionnaires and the resultant lack of data. Overall, the completion rates were good, with the most notable exception being the preanaesthesia questionnaire (at time point S4). Many patients did not have the opportunity to complete the questionnaire at this point as they went from theatre reception to anaesthetic room without waiting.

To compensate for the effects of this missing data, the AUC statistic was employed, however it is not possible to draw firm conclusions regarding the experience of anxiety minutes prior to anaesthetic induction.

\section{Conclusion}

This study found higher rates of anxiety than previously reported in gynaecological patients. Uncertainty is evident in the literature regarding the time point at which the impending surgical procedure affects patients' anxiety levels but the findings from this study suggest that anxiety levels may be elevated well before admission to hospital. Further research that aims to resolve this uncertainty is necessary due to the important implications this has for clinical practice as well as the timing of psychological interventions. It may be possible to identify a specific sector of this vulnerable population who are at particular risk of high levels of anxiety using variables such as trait anxiety, type of surgery, and pain prior to admission. Recognizing the support, other patients can give, through affiliation, and ensuring that nursing care is individualized can also make a positive contribution.

Aspects of the organization and delivery of care could be particularly stressful and policies were not always patient focused. At this hospital, improvements have been made as this study finished including encouraging patients to wear their day clothes and walk to the operating theatre, where possible, rather than being wheeled on a trolley. The provision of individualized patient care that recognizes and helps maintain personal identity and control facilitates the alleviation of anxiety. The provision of patient services, informed by patients' experiences and point of view, is likely to offer care that better means their needs.

\section{Acknowledgements}

Grateful thanks to all the women who gave their time to participate in this study. To the members of the steering group overseeing this study: Dr Christine Cox, Dr Richard Barrett and Dr Nigel North. This study was kindly funded by a grant from the BUPA Foundation. 


\section{Contributions}

Study design: EC, KB; data collection and analysis: SA, PS; manuscript preparation: SA, KB, EC.

\section{References}

Abbott J \& Abbott P (1995) Psychological and cardiovascular predictors of anaesthesia induction, operative and post-operative complications in minor gynaecological surgery. British Journal of Clinical Psychology 34, 613-623.

Aksoy FM, Özedemir A \& Yavuz Y (2000) Invasiveness of radiological procedures: state-trait anxiety in women undergoing 3 different investigations and 3-month follow-up. Turkish Journal of Medical Science 30, 595-599.

Altman DG (1991) Practical Statistics for Medical Research. Chapman and Hall, London, UK.

Appleton C (1993) The art of nursing: the experience of patients and nurses. Journal of Advanced Nursing 18, 892-899.

Aronson J (1994) A pragmatic view of thematic analysis. The Qualitative Report 2, Spring. [http://www.nova.edu/ssss/QR/ BackIssues/QR2-1/aronson.html accessed 9-09-04]

Astedt-Kurki P \& Haggman-Laitila A (1992) Good nursing practice as perceived by clients: a starting point for the development of professional nursing. Journal of Advanced Nursing 17, 11951199.

Badner NH, Nielson WR, Munk S, Kwiatkowska C \& Gelb AW (1990) Preoperative anxiety: detection and contributing factors.

15 Canadian Journal of Anaesthesia 37, 444-447.

Barbour RS (1999) The case for combining qualitative and quantitative approaches in health services research. Journal of Health Services Research and Policy 4, 39-43.

Barriball KL \& While A (1994) Collecting data using a semi-structured interview: a discussion paper. Journal of Advanced Nursing 19, 328-335.

Barriball KL, Christian SL, While AE \& Bergen A (1996) The telephone survey method: a discussion paper. Journal of Advanced

16 Nursing 24, 115-121.

Biley FC (1989) Nurses' perception of stress in preoperative surgical patients. Journal of Advanced Nursing 14, 575-581.

Boeke S, Stronks D, Verhage F \& Zwaveling A (1991) Psychological variables as predictors of the length of post-operative hospitalisation. Journal of Psychosomatic Research 35, 281-288.

Briggs M \& Dean K (1998) A qualitative analysis of the nursing documentation of postoperative pain management. Journal of Clinical Nursing 7, 155-163.

Carr ECJ (2000) Exploring the effect of postoperative pain on patient outcomes following surgery. Acute Pain 3, 183-193.

Carr ECJ \& Worth A (2001) The use of the telephone interview for research. NT Research 6, 511-523.

Caumo W, Schmidt AP, Schneider CN \& Bergmann J (2001) Risk factors for preoperative anxiety in adults. Acta Anaesthesiologica

17 Scandinavica 45, 298-307.

Chapman CRC, Dubner R, Foley KM, Gracely RH \& Reading AE (1985) Pain measurement: an overview. Pain 22, 1-31.

Cheung LH, Callaghan P, Chang AM (2003) A controlled trial of psycho-educational interventions in preparing Chinese women for elective hysterectomy. International Journal of Nursing Studies 40, 207-216.

Choiniere M, Rittenhouse BE, Perreault S, Chartrand D, Rousseau P, Smith B \& Pepler B (1998) Efficacy and costs of a patientcontrolled analgesia versus regularly administered intramuscular

18 opioid therapy. Anaesthesiology 89, 1377-1388.

Coll AM, Ameen JM \& Mead D (2004) Postoperative pain assessment tools in day case surgery: literature review. Journal of Advanced Nursing 46, 124-133.

Cunado Barrio A, Gil ML, Caston JR, De La Torre JS, Martinez LC, Garcia Lopez F (1999) The effect of a structured, individualized "nursing visit" on the anxiety of surgical patients. A randomized clinical study [Spanish]. Enfermeria Clinica. 9, 98-104, 1999 May-Jun. (25 ref).

De Groot KI, Boeke S, Van Der Berge HJ, Duivenvoorden HJ, Bonke B \& Passchier J (1997) Assessing short- and long-term recovery from lumbar surgery with pre-operative biographical medical and psychological variables. British Journal of Health Psychology 2, 229-243.

Devine EC (1992) Effects of psychoeducational care for adult surgical patients: a meta-analysis of 191 studies. Patient Education and Counselling 19, 129-142.

Dodds F (1993) Access to the coping strategies managing anxiety in

19 elective surgical patients. Professional Nurse ?????, 45-52.

Duits AA, Duivenvoorden HJ, Boeke S \& Taams MA (1998) The course of anxiety and depression in patients undergoing coronary artery bypass graft surgery. Journal of Psychosomatic Research 45,

20 127-138.

EGRET. CYTEL SOFTWARE Corp. 675 Massachusetts Ave. Cambridge. MA 02139. USA.

Ersser SJ (1998) The presentation of the nurse: a neglected dimension of the therapeutic nurse-patient interaction? In Nursing as Therapy, 2nd edn (McMahon R \& Pearson A eds). Stanley Thornes, Cheltenham, pp. 37-63.

Gammon J \& Mulholland CW (1996) Effects of preparatory information prior to elective total hip replacement on psychological coping outcomes. Journal of Advanced Nursing 24, 303308.

Green JC, Caracelli VJ \& Graham WF (1994) Towards a conceptual framework for mixed-method evaluation designs. Educational

21 Evaluation and Political Analysis 11, 255-274.

Grieve RJ (2002) Day surgery preoperative anxiety reduction and coping strategies. British Journal of Nursing 11, 670-678.

Gudex C, Dolan P, Kind P \& Williams A (1996) Health status valuations from the general public using the Visual Analogue Scale. Quality of Life Research 5, 521-531.

Holloway I \& Wheeler S (1996) Qualitative Research for Nurses. Blackwell Science, Oxford.

Ivarsson B, Larsson S \& Sjoberg T (2004) Postponed or cancelled heart operations from the patient's perspective. Journal of Nursing Management 12, 28-36.

Jick TD (1979) Mixing qualitative and quantitative methods: triangulation in action. Administrative Science Quarterly 24, 602-611.

Johnston M (1980) Anxiety in surgical patients. Psychological Medicine 10, 145-152.

Johnston M \& Vogele C (1993) Benefits of psychological preparations for surgery: a meta-analysis. Annals of Behavioral Medicine $15,245-256$. 
Kain ZN, Sevarino F, Alexander GM, Pincus S \& Mayes LC (2000) Preoperative anxiety and postoperative pain in women undergoing hysterectomy a repeated-measures design. Journal of Psychosomatic Research 49, 417-422.

Kalkman CJ, Visser K, Moen J, Bonsel GL, Grobbee DE, Moons KGM (2003) Preoperative predictors of severe postoperative pain. Pain 105, 415-423.

Kiecolt-Glaser JK, Page GG, Marucha PT, Maccallum RD \& Glaser $\mathrm{R}$ (1998) Psychological influences in surgical recovery. American Psychologist 53, 1209-1218.

Kincey J (1995) Surgery. In Health Psychology - Processes and Applications, 2nd edn (Broome A \& Llewelyns S eds). Chapman and Hall, London, pp. 391-403.

Kindler CH, Harms C, Amsler F, Ihde-Scholl T \& Scheidegger D (2000) The visual analog scale allows effective measurement of preoperative anxiety and detection of patients' anesthetic concerns. Anesthesia Analgesia 90, 706-712.

Knight RG, Waal-Manning HJ \& Spears GF (1983) Some norms and reliability data for the State-Trait Anxiety Inventory and the Zung self rated depression scale. British Journal of Clinical Psychology 22, 245-249.

Koch T, Webb C \& Williams AM (1995) Listening to the voices of older patients: an existential-phenomenological approach to quality assurance. Journal of Clinical Nursing 4, 185-193.

Koivula M, Tarrka M, Tarrka M, Laipala P \& Paunonen-Ilmonen M (2002) Fear and anxiety in patients at different time-points in the coronary artery bypass process. International Journal of Nursing Studies 39, 811-822.

Kulik JA, Mahler HIM \& Moore PJ (1996) Social comparison and affiliation under threat: effects on recovery from major surgery. Journal of Personality and Social Psychology 71, 967-979.

Lalinec MM \& Engelsmann F (1985) Anxiety, fears and depression related to hysterectomy. Canadian Journal of Psychiatry 30, 44 47.

Manias E (2003) Pain and anxiety management in the postoperative gastro-surgical setting. Journal of Advanced Nursing 41, 585-594.

McCrone S, Lenz E, Tarzian A \& Perkins S (2001) Anxiety and depression: incidence and patterns in patients after coronary artery bypass graft surgery. Applied Nursing Research 14, 155-164.

McDowell I \& Newell C (1987) Measuring Health: A Guide to Rating Scales and Questionnaires. Oxford University Press, Oxford.

Miles MB \& Huberman AM (1994) Qualitative Data Analysis:

22 An Expanded Sourcebook, 2nd edn. Sage Publications, ??????.

MINITAB Inc., 3081 Enterprise Drive, State College, PA 168013008. USA.

Mitchell ML (2000) Psychological preparation for patients undergoing day case surgery. Ambulatory Surgery 8, 19-30.

Moser DK, Chung ML, McKinley S, Riegel BAK, Cherrington CC, Blakely W, Biddle M, Frazier SK \& Garvin BJ (2003) Critical care nursing practice regarding patient anxiety assessment and management. Intensive \& Critical Care Nursing 19, 276-288.

Munafo MR \& Stevenson J (2001) Anxiety and surgical recovery reinterpreting the literature. Journal of Psychosomatic Research 51, 589-596.

Nelson FV, Zimmerman L, Barnason S, Nieveen J \& Schmaderer M (1998) The relationship and influence of anxiety on postoperative pain in the coronary artery bypass graft patient. Journal of Pain and Symptom Management 15, 102-109.
Nijkamp MD, Kenens CA, Dijker AJM, Ruiter RAC, Hiddema F \& Nuijts RMMA (2004) Determinants of surgery related anxiety in cataract patients. British Journal of Opthalmology 88, 1310-1314.

Norman GR \& Streiner DL (2000) Biostatistics: The Bare Essentials. BC Decker Inc., Hamilton, Ontario Canada.

Norris W \& Baird WLM (1967) Pre-operative anxiety: a study of the incidence and aetiology. British Journal of Anaesthesia 39, 503509.

Osborn TM \& Sandler NA (2004) The effects of preoperative anxiety on intravenous sedation. Anaesthesia Progress 51, 46-51.

Paraho AK (1997) Nursing Research: Principles, Process and Issues. Macmillan Press Ltd, Basingstoke.

Parent N \& Fortin F (2000) A randomized, controlled trial of vicarious experience through peer support for male first-time cardiac surgery patients: impact on anxiety, self-efficacy expectation, and self-reported activity. Heart and Lung 29, 389-400.

Perry F, Parker RK, White PF \& Clifford A (1994) Role of psychological factors in postoperative pain control and recovery with patientcontrolled analgesia. The Clinical Journal of Pain 10, 57-63.

Ramsey MAE (1972) A survey of pre-operative fear. Anaesthesia 27, 396-402.

Ryan MM, Dennerstein L \& Pepperel R (1989) Psychological aspects of hysterectomy: a prospective study. British Journal of Psychiatry 154, 516-522.

Salmon P (1993) the reduction of anxiety in surgical patients: an important nursing task or the medicalisation of preparatory worry? International Journal of Nursing Studies 30, 323-330.

Salmon P, Evans R \& Humphrey DE (1986) Anxiety and endocrine changes in surgical patients. British Journal of Clinical Psychology 25, 135-141.

Salter JR (1985) Gynaecological symptoms and psychological distress in potential hysterectomy patients. Journal of Psychosomatic Research 29, 155-159.

Senn S, Stevens L \& Chaturvedi N (2000) Repeated measures in clinical trials: simple strategies for analysis using summary measures. Statistics in Medicine 19, 861-877.

Shih FJ (1998) Triangulation in nursing research: issues of conceptual clarity and purpose. Journal of Advanced Nursing 28, 631-641.

Sjoling M, Nordahl G, Olofsson N \& Asplund K (2003) The impact of preoperative information of state anxiety, postoperative pain and satisfaction with pain management. Journal of Education and Counselling 51, 169-176.

Spielberger CD \& Rickman RL (1990) Assessment of state and trait anxiety. In Anxiety Psychobiological and Clinical Perspectives (Sartorius N, Andreoli V, Cassano G, Eisenberg L, Kielholz P, Pancheri P \& Racagni G eds). Hemisphere Publishing Corporation, ?????????, pp. 69-82.

Spielberger CD, Gorsuch RL \& Lushene RE (1970) STAI Manual for the State-Trait Anxiety Inventory. Consulting Psychologists Press, 25 Inc., ???????.

Spielberger CD, Gorsuch RL, Lushene RE, Vagg P \& Jacobs G (1983) Stait-Trait Anxiety Inventory. Mind Garden, Inc., Palo Alto, California.

SPSS Inc. 233 S. Wacker, 11th Floor, Chicago. IL 60606-6307.

Swindale JE (1989) The nurse's role in giving pre-operative information to reduce anxiety in patients admitted to hospital for elective minor surgery. Journal of Advanced Nursing 14, 899-905. 
Tasa K, Baker GR \& Murray M (1996) Using patient feedback for quality improvement. Quality Management in Health Care 4, 55-67.

Tatrow K, Montgomery GH, Avellino M, Bovbjerg DH (2004) Activity and sleep contribute to levels of anticipatory distress in breast surgery patients. Behavioral Medicine 30, 85-91.

Teasdale K (1995) Theoretical and practical considerations on the use of reassurance in the nursing management of anxious patients. Journal of Advanced Nursing 22, 79-86.

Teasdale K, Mulraney S, Blanchard H, Rolfe J \& Pallett S (2000) An analysis of the ability of nurses to identify the anxiety levels of patients in general medical and surgical wards. Nursing Times Research 5, 364-370.

Thomas VJ, Heath M, Rose D \& Flory P (1995) Psychological characteristics and the effectiveness of patient-controlled analgesia. British Journal of Anaesthesia 74, 271-276.

Ukpong DI \& Adesunkanmi AR (2004) Psychiatric symptoms in surgical patients: an assessment of the course of anxiety. Nigerian Postgraduate Medical Journal 11, 75-78.

Van den Bosch JE, Moons KG, Bonsel GJ \& Kalkman CJ (2005) Does measurement of preoperative anxiety have added value for predicting postoperative nausea and vomiting? Anesthesia and

26

Walsgrove H (1999) A sanctuary from anxiety. Nursing Standard 14, 61.

Waterman H, Leatherbarrow B, Slater R \& Waterman C (1999) Post-operative pain, nausea and vomiting: qualitative perspectives from telephone interviews. Journal of Advanced Nursing 29, 690696.

Webb C (1986) Women as gynaecology patients and nurses. In Feminist Practice in Women's Health Care (Webb C ed.). Wiley, Chichester, pp. 93-112.

Welsh J (2000) Reducing patient stress in theatre. British Journal of Perioperative Nursing 10, 321-327.

Wilson-Barnett J (1981) Anxiety in hospitalised patients. Royal Society of Health 101, 118-122.

Wilson-Barnett J (1994) Preparing patients for invasive medical and surgical procedures 3: policy implications for implementing specific psychological interventions. Behavioural Medicine 20, 23-26.

Wilson-Barnett J \& Batehup L (1988) Patient Problems: A Research Base for Nursing Care. Scutari Press, London. 


\section{Author Query Form}

\section{Journal: $\quad$ JCN}

\section{Article: $\quad 1285$}

Dear Author,

During the copy-editing of your paper, the following queries arose. Please respond to these by marking up your proofs with the necessary changes/additions. Please write your answers on the query sheet if there is insufficient space on the page proofs. Please write clearly and follow the conventions shown on the attached corrections sheet. If returning the proof by fax do not write too close to the paper's edge. Please remember that illegible mark-ups may delay publication.

Many thanks for your assistance.

\begin{tabular}{|c|c|c|}
\hline $\begin{array}{l}\text { Query } \\
\text { reference }\end{array}$ & Query & Remarks \\
\hline 1 & $\begin{array}{l}\text { Au: Nijkamp et al } 2005 \text { has not been included in the list, please supply } \\
\text { publication details. }\end{array}$ & \\
\hline 2 & $\begin{array}{l}\text { Au: 'Osbourne and Sandler (2004)' changed to 'Osborn and Sandler } \\
\text { (2004)' as per list. Please check. }\end{array}$ & \\
\hline 3 & $\begin{array}{l}\text { Au: 'Kielcolt-Glaser et al. (1998)' changed to 'Kiecolt-Glaser et al. } \\
\text { (1998)' as per list. Please check. }\end{array}$ & \\
\hline 4 & $\begin{array}{l}\text { Au: Van den Bosch } 2005 \text { has not been included in the list, please } \\
\text { supply publication details. }\end{array}$ & \\
\hline 5 & $\begin{array}{l}\text { Au: 'de Groot et al. (1997)' changed to 'De Groot et al. (1997)' as per } \\
\text { list. Please check throughout the article. }\end{array}$ & \\
\hline 6 & $\begin{array}{l}\text { Au: Green \& McClintock } 1985 \text { has not been included in the list, } \\
\text { please supply publication details. }\end{array}$ & \\
\hline 7 & $\begin{array}{l}\text { Au: 'Parahoo (1997)' changed to 'Paraho (1997)' as per list. Please } \\
\text { check. }\end{array}$ & \\
\hline 8 & $\begin{array}{l}\text { Au: Coyle \& Williams } 2000 \text { has not been included in the list, please } \\
\text { supply publication details. }\end{array}$ & \\
\hline 9 & $\begin{array}{l}\text { Au: 'Speilberger et al. (1983)' changed to 'Spielberger et al. (1983)' as } \\
\text { per list. Please check. }\end{array}$ & \\
\hline 10 & $\begin{array}{l}\text { Au: 'McDowell and Newall (1987)' changed to 'McDowell and } \\
\text { Newell (1987)' as per list. Please check. }\end{array}$ & \\
\hline 11 & $\begin{array}{l}\text { Au: Spielberger et al. } 1973 \text { has not been included in the list, please } \\
\text { supply publication details. }\end{array}$ & \\
\hline 12 & $\begin{array}{l}\text { Au: Please check the sentence 'The variation between patients...' for } \\
\text { rearrangement of words has been done. }\end{array}$ & \\
\hline
\end{tabular}




\begin{tabular}{|c|c|}
\hline 13 & $\begin{array}{l}\text { Au: 'Abbott and Abbott (1985)' changed to 'Abbott and Abbott } \\
\text { (1995)' as per list. Please check. }\end{array}$ \\
\hline 14 & $\begin{array}{l}\text { Au: Bouthillette } 2001 \text { has not been included in the list, please supply } \\
\text { publication details. }\end{array}$ \\
\hline 15 & $\begin{array}{l}\text { Au: Badner, Nielson, Munk, Kwiatkowska, Gelb (1990) not cited. } \\
\text { Please cite reference in text or delete from the list. }\end{array}$ \\
\hline 16 & $\begin{array}{l}\text { Au: Barriball, Christian, While, Bergen (1996) not cited. Please cite } \\
\text { reference in text or delete from the list. }\end{array}$ \\
\hline 17 & $\begin{array}{l}\text { Au: Caumo, Schmidt, Schneider, Bergmann (2001) not cited. Please } \\
\text { cite reference in text or delete from the list. }\end{array}$ \\
\hline 18 & $\begin{array}{l}\text { Au: Choiniere, Rittenhouse, Perreault, Chartrand, Rousseau, Smith, } \\
\text { Pepler (1998) not cited. Please cite reference in text or delete from the } \\
\text { list. }\end{array}$ \\
\hline 19 & Au: Please provide volume number. \\
\hline 20 & $\begin{array}{l}\text { Au: Duits, Duivenvoorden, Boeke, Taams (1998) not cited. Please cite } \\
\text { reference in text or delete from the list. }\end{array}$ \\
\hline 21 & $\begin{array}{l}\text { Au: Green, Caracelli, Graham (1994) not cited. Please cite reference in } \\
\text { text or delete from the list. }\end{array}$ \\
\hline 22 & Au: Please provide location of the publisher 'Sage Publications'. \\
\hline 23 & $\begin{array}{l}\text { Au: Nijkamp, Kenens, Dijker, Ruiter, Hiddema, Nuijts (2004) not } \\
\text { cited. Please cite reference in text or delete from the list. }\end{array}$ \\
\hline 24 & $\begin{array}{l}\text { Au: Please provide location of the publisher 'Hemisphere Publishing } \\
\text { Corporation'. }\end{array}$ \\
\hline 25 & $\begin{array}{l}\text { Au: Please provide location of the publisher 'Consulting Psychologists } \\
\text { Press, Inc.' }\end{array}$ \\
\hline 26 & $\begin{array}{l}\text { Au: Van den Bosch, Moons, Bonsel, Kalkman (2005) not cited. Please } \\
\text { cite reference in text or delete from the list. }\end{array}$ \\
\hline
\end{tabular}




\section{Please correct and return this set}

Please use the proof correction marks shown below for all alterations and corrections. If you wish to return your proof by fax you should ensure that all amendments are written clearly in dark ink and are made well within the page margins.

\begin{tabular}{|c|c|c|}
\hline Instruction to printer & Textual mark & Marginal mark \\
\hline Leave unchanged & ... under matter to remain & Stet \\
\hline $\begin{array}{l}\text { Insert in text the matter } \\
\text { indicated in the margin }\end{array}$ & $h$ & New matter followed by \\
\hline Delete & $\mapsto$ through matter to be deleted & $\delta$ \\
\hline Delete and close up & E through matter to be deleted & की \\
\hline $\begin{array}{l}\text { Substitute character or } \\
\text { substitute part of one or } \\
\text { more word(s) }\end{array}$ & $\begin{array}{l}/ \text { through letter or } \mapsto \text { through } \\
\text { word }\end{array}$ & New letter or new word \\
\hline Change to italics & - under matter to be changed & لس \\
\hline Change to capitals & $\equiv$ under matter to be changed & $\equiv$ \\
\hline Change to small capitals & $=$ under matter to be changed & $=$ \\
\hline Change to bold type & m under matter to be changed & $m$ \\
\hline Change to bold italic & $\bar{\approx}$ under matter to be changed & 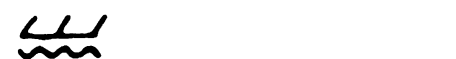 \\
\hline Change to lower case & Encircle matter to be changed & $\#$ \\
\hline Change italic to upright type & (As above) & \\
\hline Insert 'superior' character & $\begin{array}{l}/ \text { through character or } \wedge \text { where } \\
\text { required }\end{array}$ & $\begin{array}{l}\text { y under character } \\
\text { e.g. } 2 y\end{array}$ \\
\hline Insert 'inferior' character & (As above) & $\boldsymbol{L}$ over character e.g. $\mathbf{2}$ \\
\hline Insert full $\mathrm{s}$ & (As abc & ○ \\
\hline Insert comma & (As above) & , \\
\hline Insert single quotation marks & (As abo & $y$ and/or $y$ \\
\hline $\begin{array}{l}\text { Insert double quotation } \\
\text { marks }\end{array}$ & (As above) & $\ddot{y}$ and/or $y$ \\
\hline Insert hyphen & (As : & (4y) \\
\hline Start new paragraph & $\sqrt{-10}$ & $\overline{5}$ \\
\hline No new paragraph & 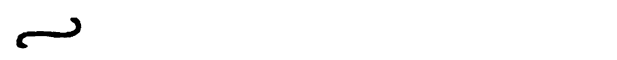 & 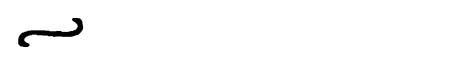 \\
\hline Transpose & حـ & 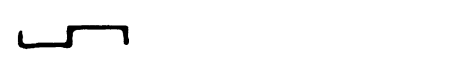 \\
\hline Close up & linking : & $=$ \\
\hline Insert space between letters & $\boldsymbol{h}$ between letters af & $\#$ \\
\hline Insert space between words & $\boldsymbol{h}$ between words affected & $\#$ \\
\hline Reduce space between letters & $\uparrow$ between letters affected & $T$ \\
\hline Reduce space between words & $\tau$ between words affected & \\
\hline
\end{tabular}

